Formatif: Jurnal Ilmiah Pendidikan MIPA

Vol. 8, No. 3, Desember 2018, pp. 175-184

p-ISSN: 2088-351X

e-ISSN: 2502-5457

DOI: http://dx.doi.org/10.30998/formatif.v8i3.2751

\title{
Exploration of Ethnomathematics of House and Traditional Music Tools Biak-Papua Cultural
}

\author{
Eksplorasi Etnomatematika Rumah dan Alat Musik Tradisional Masyarakat \\ Biak-Papua
}

\author{
Alvian M. Sroyer (*) \\ Universitas Cendrawasih, Papua \\ Jonner Nainggolan \\ Universitas Cendrawasih, Papua \\ Ida M. Hutabarat \\ Universitas Cendrawasih, Papua
}

\begin{abstract}
Received: September 3,2018 This research is an ethnomathematics study of the Biak Papuan Revised: October 24,2018 community. The ethnomathematics studied are houses and traditional Accepted: October 26, 2018 musical instruments. The shape and style of the traditional Biak house still remain to this day. The purpose of this study was to examine and reveal the relationship between mathematics and the traditional home culture of the Biak community, namely rum Som, rum Sram and Sram Mankubui and traditional musical instruments namely Tifa. The research method used is an exploratory survey method with a qualitative approach. The results showed that the shape of the roof of rum Som, rum Sram, Sram Mankubui was rectangular, half elliptical and triangular trapezoid. Whereas Tifa's musical instruments look like the two most belted cones combined.
\end{abstract}

Keywords: etnomathematics, traditional houses roof, musical instruments and the Biak community

(*) Corresponding Author: $\quad$ sroyeralvian@gmail.com

How to Cite: Sroyer, A.M., Nainggolan, J., \& Hutabarat, I.M. (2018). Exploration of ethnomathematics of house and traditional music tools Biak-Papua cultural. Formatif: Jurnal Ilmiah Pendidikan MIPA, 8 (3): 175-184. http://dx.doi.org/10.30998/formatif.v8i3.2751

\section{PENDAHULUAN}

Belajar matematika bukan hanya tentang memperoleh, menguasai komputasi, masalah teknik, dan pemecahannya atau hanya tentang memahami definisi, argumen, serta bukti. Namun matematika perlu keterlibatan seseorang dalam merekonstruksi pemikiran selayaknya seorang matematikawan (Heather, 2003). Kanh (2003) menegaskan bahwa pembelajaran Matematika mengharuskan seseorang agar dapat mengembangkan cara berpikir secara matematis. Jonh (1998) menambahkan, ada persepsi bahwa matematika adalah alat yang efektif untuk menganalisis, memeriksa, dan mem-verifikasi kebenaran. Kehidupan manusia tetap tidak lengkap tanpa matematika (James, 1982). Matematika adalah aktivitas manusia yang berhubungan dengan pola, pemecahan masalah, pemikiran logis, dan seterusnya, dengan tujuan untuk memahami dunia (Glorin, 1980). Matematika adalah asubjek universal, di antaranya setiap budaya memiliki konsep 
Formatif: Jurnal Ilmiah Pendidikan MIPA

Vol. 8, No. 3, Desember 2018, pp. 175-184

p-ISSN: 2088-351X

e-ISSN: 2502-5457

DOI: http://dx.doi.org/10.30998/formatif.v8i3.2751

angka dan gagasan bahwa $1+1=2$, tidak peduli seberapa maju teknologi budaya. Gagasan universalitas tentang matematika lebih diperkuat oleh fakta bahwa ditemukan di seluruh dunia, di banyak tempat, dan waktu yang berbeda. Sedangkan Etnomatematika menurut D'Ambrosio (1985) adalah suatu pengetahuan matematika akademik yang dikembangkan oleh berbagai sektor masyarakat serta dengan mempertimbangkan modus yang berbeda di mana budaya yang berbeda merundingkan praktik matematika (cara mengelompokkan, berhitung, mengukur, merancang bangunan atau alat, bermain, dan lainnya).

Etnomatematika sering dan banyak sekali digunakan dalam masyarakat khususnya di Indonesia. Hampir seluruh kehidupan masyarakat di Indonesia menggunakan etnomatematika dalam menjalani kehidupan bermasyarakat (Aditya, 2018). Indonesia memiliki kurang lebih 416 suku, salah satunya suku Biak di Papua (Komandoko, 2010). Suku Biak merupakan suku yang dikenal sebagai penjelajah laut. Dalam menjelajah, suku ini pada akhirnya harus bersentuhan langsung dengan para pelaut Ternate, Tidore, Halmahera-Flores-Gebe, Sulawesi, Buton, pelaut Tiongkok, dan Eropa. Hal ini membuat masyarakat Biak cepat mengalami perkembangan dibandingkan masyarakat Papua pada umumnya. Walaupun cepat dalam perkembangannya, tetapi tidak memengaruhi budaya masyarakat setempat. Hal ini terlihat dari bentuk dan corak rumah serta alat musik tradisional yang masih tetap ada dan dilestarikan (Albert Rumbekwan, 2014). Beberapa rumah tradisional yang dikenal di antaranya rum som, rum sram, dan sram mankubui, serta alat musik tifa.

Keterkaitan antara matematika dan budaya khususnya terlihat pada atap rumah tradisional serta alat musik masyarakat Biak. Bentuk atap rumah tradisional menggunakan konsep geometri seperti trapesium, persegi panjang, dan setengah elips. Sedangkan dinding, lantai, pintu, serta jendela berbentuk persegi panjang dan bujur sangkar. Alat musik tradisional (tifa) merupakan bentuk geometri dari kerucut terpancung. Tifa terlihat seperti dua buah kerucut terpancung yang digabung, di mana bagian atas dan bawah ukurannya berbeda.

Atap rumah rum som, rum sram, dan sram mankubui, serta alat musik tifa memiliki ciri khas yang berbeda dengan rumah khas dan alat musik daerah lainnya di Indonesia. Tanpa disadari, terdapat etnomatematika yang sangat jarang diketahui orang, sehingga penulis tertarik dan berupaya untuk mengkaji lebih jauh terutama dalam rancang bangun rumah bentuk geometri dengan nilai etnomatimatika secara lengkap dan lebih rinci. Dengan harapan bahwa etnomatematika atap rumah rum som, rum sram, dan sram mankubui, serta alat musik tifa tidak dilupakan atau bahkan hilang seiring dengan perkembangan zaman dan dapat diintegrasikan pada kurikulum sampai pada rencana serta pelaksanaan pembelajaran di kelas sehingga dapat lebih dipahami oleh peserta didik, karena lebih disesuaikan dengan konteks masyarakat Biak. Sekaligus membantu peserta didik meningkatkan kemampuan matematika dalam berbagai konteks, dapat berpikir secara matematis menurut budaya dan tradisi mereka.

\section{METODE}

Pendekatan penelitian ini, adalah dengan studi kualitatif deskriptif. Tujuan penggunaan studi kualitatif deskriptif adalah mengungkapkan dan memperoleh informasi dari tokoh tradisional (Manawir), tokoh masyarakat (ahli, akademisi, dan seniman yang lahir pada 1950-an). Kasus yang diteliti dalam penelitian ini adalah etnomatematika rumah tradisional dan alat musik tradisional masyarakat Biak. Pada penelitian kualitatif yang menjadi instrumen penelitian adalah peneliti sendiri (Sugiono, 2009). Juga menurut 
Formatif: Jurnal Ilmiah Pendidikan MIPA

Vol. 8, No. 3, Desember 2018, pp. 175-184

p-ISSN: 2088-351X

e-ISSN: 2502-5457

DOI: http://dx.doi.org/10.30998/formatif.v8i3.2751

Musa (2007), matematika adalah pembangunan pengetahuan berkaitan dengan hubungan ruang dan waktu kualitatif dan kuantitatif. Sebagai human instrument, peneliti berfungsi sebagai orang yang menetapkan fokus penelitian, memilih informan yaitu tokoh masyarakat dan tokoh tradisional sebagai sumber data, kemudian melakukan pengumpulan data dan validasi instrumen (Kaplan dan Saccuzzo, 1993). Selain itu juga menganalisis data, menafsirkan data, dan membuat simpulan atas temuan penelitiannya. Instrumen yang telah divalidasi digunakan oleh peneliti untuk melakukan wawancara langsung dengan tokoh tradisional dan tokoh masyarakat Biak. Alur penelitian ini adalah sebagai berikut.

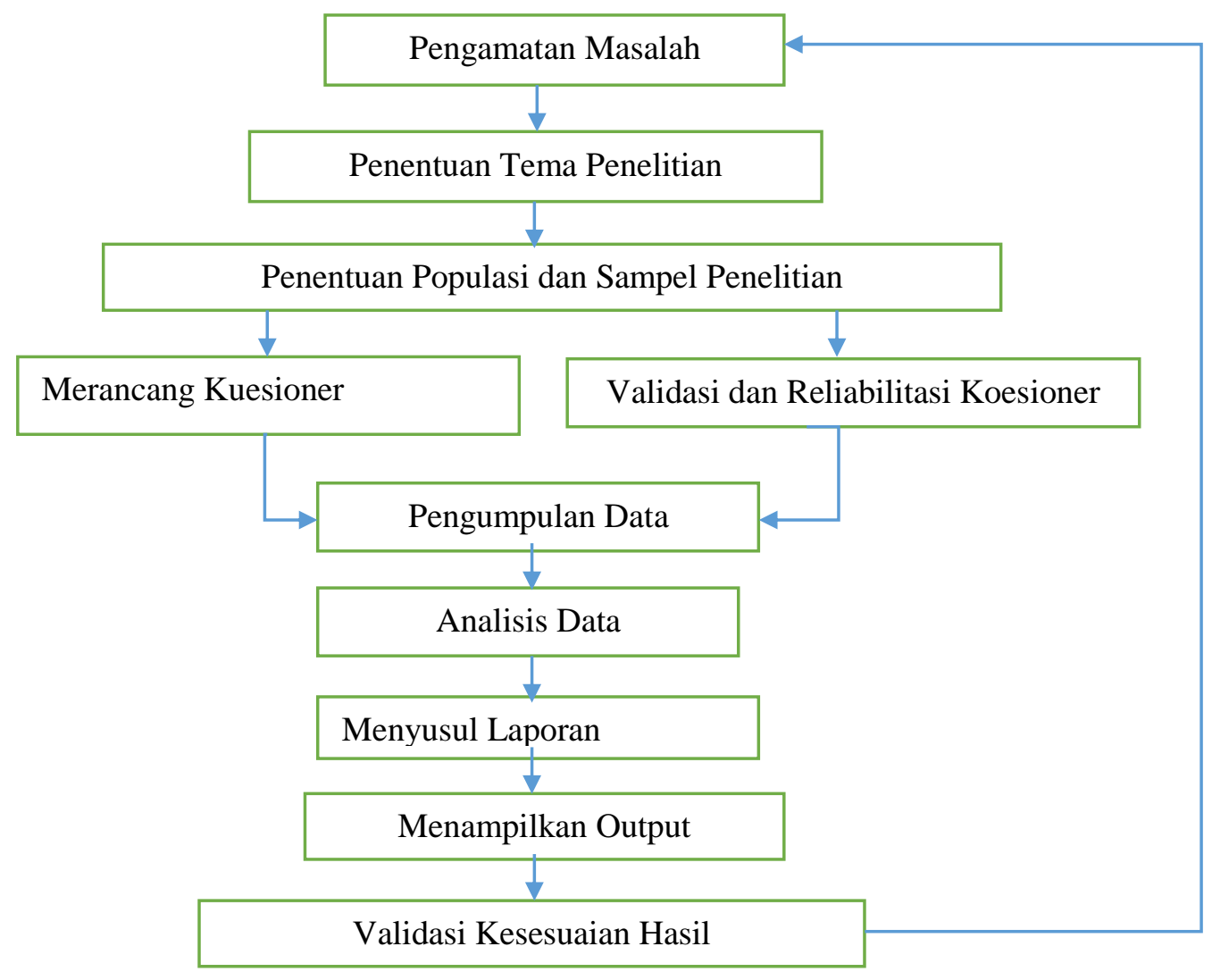

Gambar 1. Alur Penelitian

\section{HASIL DAN PEMBAHASAN}

\section{Atap Rumah Tradisional dan Alat Musik}

Atap rumah tradisional masyarakat Biak ada beberapa jenis. Namun yang dikaji hanya tiga jenis, yaitu rum som, rum sram, dan sram mankubui.

\section{Rum Som}

Rum som adalah rumah keluargayang didiami oleh orang tua dan anak-anak. Setelah dewasa dan menikah, anak perempuan mengikuti suaminya sedangkan anak lakilaki setelah menikah tetap tinggal bersama orang tuanya di rum som. Hal itu dikarenakan anak laki-laki merupakan penerus marga orang tuanya (Silas Koibur, 2018). Atap rum som dari daun sagu dan kerangka atau struktur atapnya menyerupai kulit penyu, bagian 
Formatif: Jurnal Ilmiah Pendidikan MIPA

Vol. 8, No. 3, Desember 2018, pp. 175-184

p-ISSN: 2088-351X

e-ISSN: 2502-5457

DOI: http://dx.doi.org/10.30998/formatif.v8i3.2751

depannya yang menjulur keluar dan tidak ditopang oleh tiang penyangga (gambar 2). Daun sagu mudah diperoleh dan tahan terhadap hujan serta dapat terlindung terhadap panas matahahari. Struktur atapnya menyerupai kulit penyu karena kulit penyu dianggap tahan terhadap badai laut dan panas terik matahari. Bagian dalam rum som polos tanpa ada sekat atau kamar hanya dibatasi oleh tanda yang sudah dibuat. Bagian pojok belakang rum som dibuat tungku api sebagai tempat untuk memasak. Dinding rum som dari gabah atau pelepah pohon sagu, dan lantai rumah dari kayu. Rum som dibangun dipinggir pantai, tidak jauh ke laut atau tidak terlalu dekat ke bibir pantai. Hal ini, dilakukan agar terhindar dari serangan musuh dari darat maupun dari laut.

Banyak konsep matematika tanpa disadari digunakan dalam merancang bangun rum som. Mulai dari tiang-tiang penyangga lantai, ditancap dengan jarak yang sama. Lantai dan dinding rum som berbentuk persegi panjang. Pintu dan jendela juga berbentuk persegi panjang. Bentuk dinding simetri antarsisi yang satu dengan yang lain. Bentuk Atap rum som adalah trapesium, persegi panjang, dan setengah elips. Atap rum som agak menjulur keluar tanpa tiang penyangga. Hal ini, menunjukkan konsep titip keseimbangan digunakkan dalam merancang bangun.

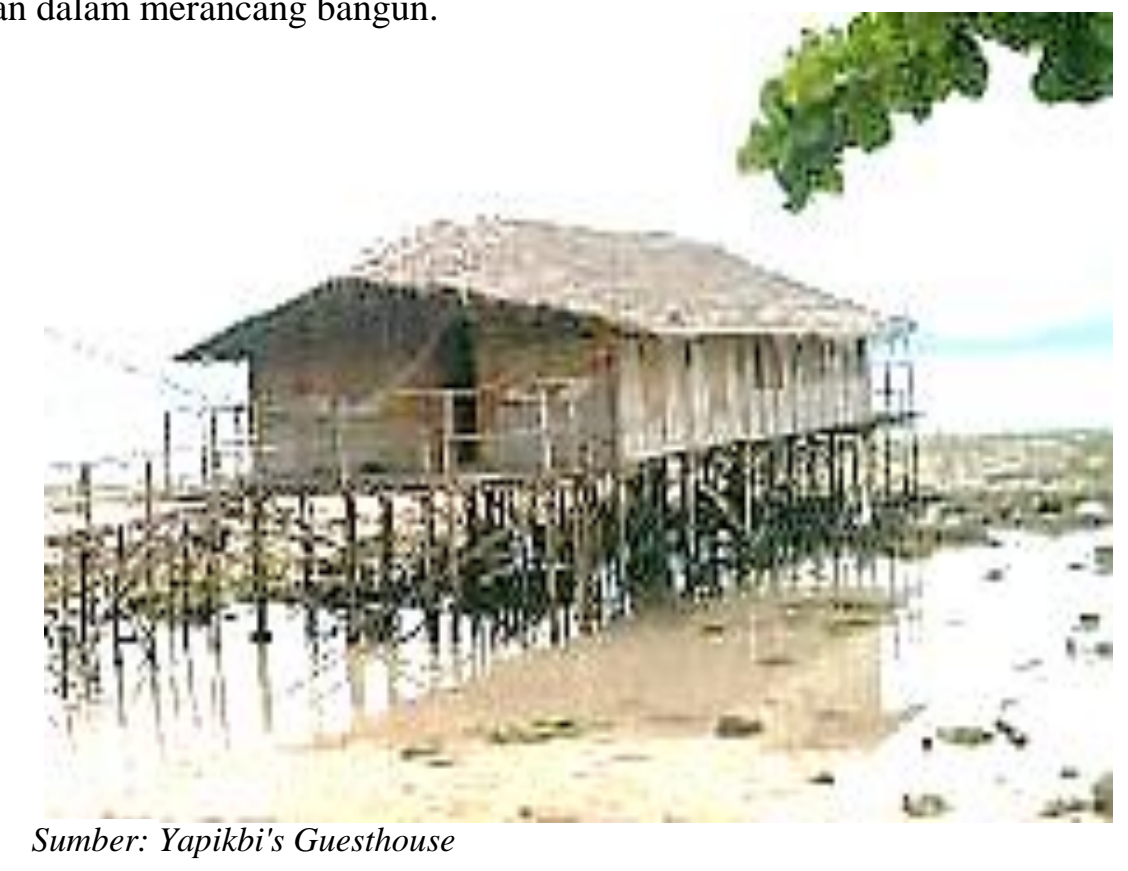

Gambar 2. Rumah Penduduk di Biak (Bentuk Rum Som)

\section{Rum Sram}

Rum sram adalah rumah pemuda. Rumah ini dibangun untuk menampung anakanak lelaki yang sudah dewasa untuk belajar. Pada rumah rum sram anak laki-laki dipersiapkan menjadi laki-laki dewasa. Mereka diajarkan bagaimana berburu, mencari ikan, dan berkebun (Silas Koibur, 2018). Bagian dalam rum sram juga polos tanpa ada sekat atau kamar, hanya dibatasi oleh tanda yang sudah dibuat atau ditetapkan. Bagian tengah rum sram dibuat tungku api sebagai tempat untuk memasak. Dinding rum sram dari gabah atau pelepah pohon sagu, dan lantai rumah dari kayu yang dibuat rata (gambar $3)$.

Banyak konsep matematika juga digunakan dalam merancang bangun rum sram. Mulai dari tiang-tiang penyangga lantai, ditancap dengan jarak yang sama. Lantai dan dinding rum sram berbentuk persegi panjang. Pintu dan jendela juga berbentuk persegi 
Formatif: Jurnal Ilmiah Pendidikan MIPA

Vol. 8, No. 3, Desember 2018, pp. 175-184

p-ISSN: 2088-351X

e-ISSN: $2502-5457$

DOI: http://dx.doi.org/10.30998/formatif.v8i3.2751

panjang. Bentuk dinding simetri antarsisi yang satu dengan yang lain. Bentuk atap rum sram adalah trapesium, persegi panjang, dan setengah elips. Bentuk geometri dari atap rum sram adalah persegi panjang dan segitiga. Sedangkan dinding, lantai, pintu, dan jendela berbentuk persegi panjang dan bujur sangkar. Jumlah jendela pada kedua dinding sama atau bisa dikatakan memiliki dinding yang simetri. Bentuk atap rum sram adalah trapesium dan segitiga. Atap rum sram juga agak menjulur keluar tanpa tiang penyangga. Hal ini menunjukkan konsep titik keseimbangan digunakkan dalam merancang bangun.

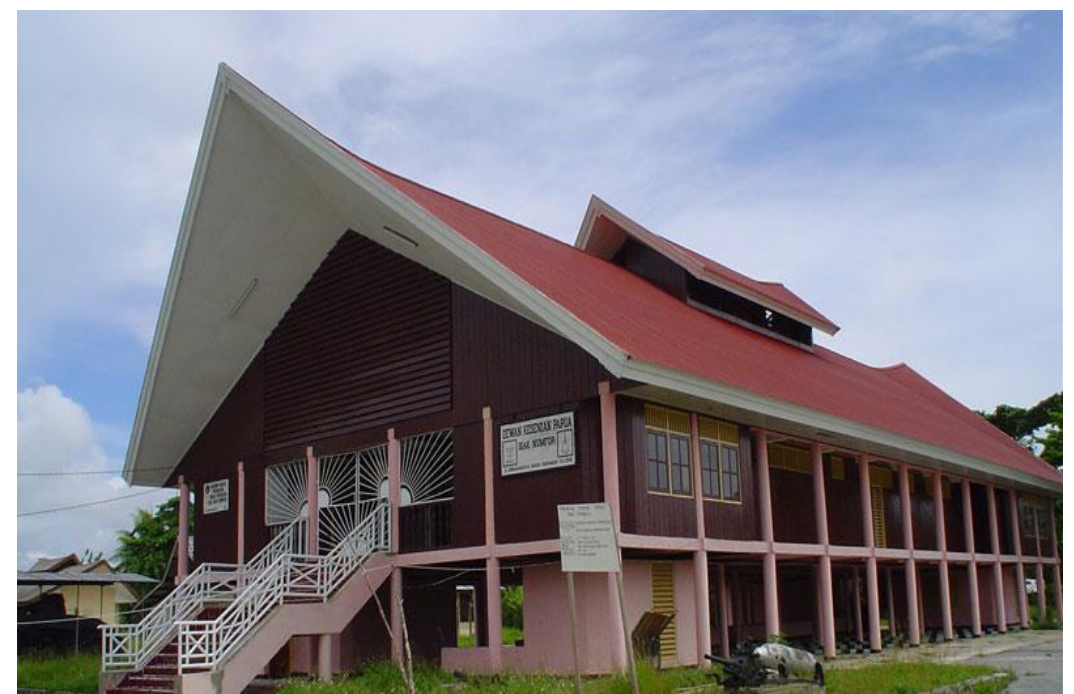

Sumber: http://www.faizal.web.id

Gambar 3. Museum Biak (Bentuk Rum Sram)

\section{Sram Mankubui}

Sram mankubui merupakan tempat para seniman bekerja. Pada tempat ini para pengukir, pemahat, dan padai besi melakukan aktivitas. Mereka membuat tifa, parang, tombak, mengukir, membuat patung, perahu, dan sebagainya (Silas Koibur, 2018). Sama halnya dengan rum som dan rum sram, bagian dalam sram mankubui polos tanpa sekat. Bagian tengah ada tungku api dan di atas tunggu dibuat para-para untuk mengeringkan kulit kayu, kulit biawak, kayu pembuat tifa, ukiran, dan sebagainya (gambar 4).

Konsep matematika juga digunakan dalam merancang bangun sram mankubui tidak jauh berbeda dari rum som dan rum sram. Mulai dari tiang-tiang penyangga lantai, ditancap dengan jarak yang sama. Dinding, pintu, dan jendela sram mankubui berbentuk persegi panjang. Namun lantainya berbentuk trapesium, sehingga ukuran dinding bagian depan lebih luas dibandingkan bagian belakang. Bentuk atap sram mankubui adalah trapesium, persegi panjang, dan setengah elips. Bentuk geometri dari atap sram mankubui adalah persegi panjang dan segitiga. Sedangkan dinding, lantai, pintu, dan jendela berbentuk persegi panjang dan bujur sangkar. Jumlah jendela pada kedua dinding sama atau bisa dikatakan memiliki dinding yang simetri. Bentuk atap sram mankubui adalah trapesium dan segitiga. Atap sram mankubui juga agak menjulur keluar tanpa tiang penyangga. Hal ini, menunjukkan konsep titik keseimbangan digunakkan dalam merancang bangun. 


\section{Formatif: Jurnal Ilmiah Pendidikan MIPA}

Vol. 8, No. 3, Desember 2018, pp. 175-184

p-ISSN: 2088-351X

e-ISSN: 2502-5457

DOI: http://dx.doi.org/10.30998/formatif.v8i3.2751

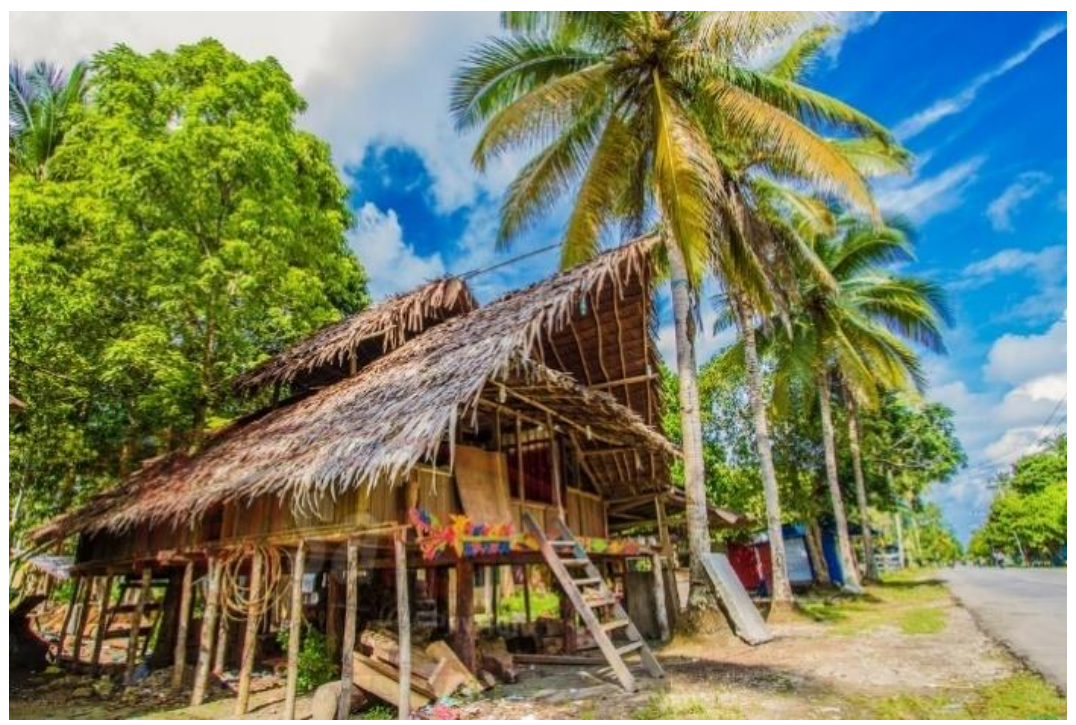

Sumber: Vicky Pongoh

Gambar 4. Bengkel Tifa Mokmer (Bentuk Sram Mankubui)

\section{Alat Musik Tradisional (Tifa)}

Tifa merupakan alat musik tradisional Papua. Alat musik yang bernama Tifa ini adalah sejenis alat musik pukul yang terbuat dari kayu. Suku-suku yang ada di Papua memiliki tifa dengan ciri khas masing-masing. Tifa biasa dimainkan saat mengiringi ritual-ritual tradisional. Alat musik tifa merupakan benda penting bagi masyarakat Papua termasuk masyarakat Biak. Tifa dimainkan dengan cara dipukul atau ditabuh, bentuknya mirip dengan gendang. Alat musik Tifa dibuat dari batang kayu yang diberi motif berupa ukiran, sehingga terlihat lebih indah. Bagian tengahnya dibuang sehingga menjadi berlubang dan pada salah satu sisinya ditutup. Kulit biawak atau soa-soa digunakan sebagai penutup dan diikat dengan tali rotan. Kulit biawak atau soa-soa sebelumnya telah dikeringkan sehingga menghasilkan bunyi yang merdu pada saat dipukul atau ditabuh. Biji damar ditempelkan di kulit biawak atau soa-soa agar suaranya makin nyaring. Berikut ini disajikan bagian-bagian Tifa masyarakat Biak.

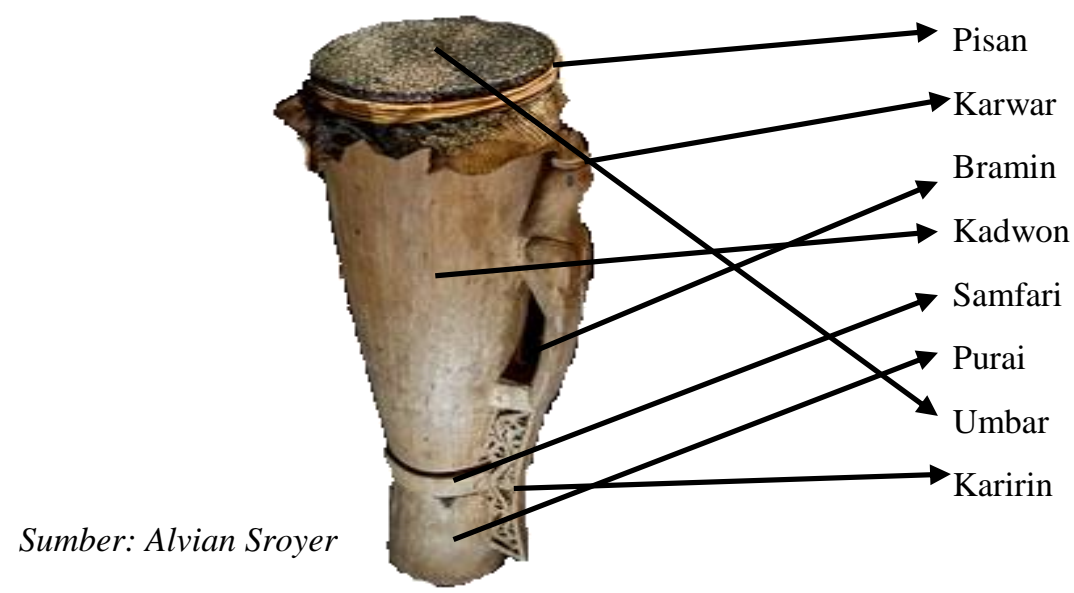

Gambar 4. Tifa dan Bagian-Bagianya 
Formatif: Jurnal Ilmiah Pendidikan MIPA

Vol. 8, No. 3, Desember 2018, pp. 175-184

p-ISSN: 2088-351X

e-ISSN: 2502-5457

DOI: http://dx.doi.org/10.30998/formatif.v8i3.2751

Pisan merupakan bagian penutup yang dipukul atau ditabuh. Karwar adalah patung yang diukir pada bagian atas pegangang tifa. Bramin merupakan pegangan tifa. Kadwon bagian atas tifa yang lebih besar yang dimaknai sebagai terang atau siang. Purai merupakan bagian bawah tifa yang lebih kecil yang dimaknai sebagai gelap atau malam hari. Samfari artinya bintang pagi, pembatas antara kadwon dan purai yang dimaknai sebagai pembatas antara gelap dan terang atau siang dan malam. Karirin bagian bawah dari pegangan (bramin) sebagai penopang bramin. Umbar adalah getah damar yang merupakan aksesoris tambahan agar punyi tifa yang dipukul lebih nyaring.

\begin{tabular}{|c|c|}
\hline $\begin{array}{c}\text { Bentuk Atap Rumah } \\
\text { dan Tifa }\end{array}$ & Bentuk Atap, Alat Musik, dan Model Matematika \\
\hline 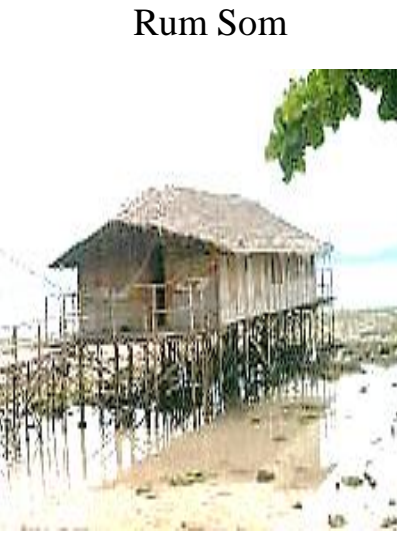 & $\begin{array}{l}\mathrm{L}=\left(\frac{\left(a+b_{1}+b_{2}+b_{3}\right)}{2} \times t\right)+(c \times d)+\left(\frac{1}{4} \pi\left(\frac{\left(b_{1}+b_{3}\right) \times d}{2}\right)\right) \\
\text { di mana } b_{2}=c\end{array}$ \\
\hline (t) & $L=\left(\frac{(a+b)}{2} \times t_{1}\right)+\left(\frac{1}{2} e \times t_{2}\right)+\left(\frac{(c+d)}{2} \times t_{3}\right)$ \\
\hline
\end{tabular}


Formatif: Jurnal Ilmiah Pendidikan MIPA

Vol. 8, No. 3, Desember 2018, pp. 175-184

p-ISSN: 2088-351X

e-ISSN: 2502-5457

DOI: http://dx.doi.org/10.30998/formatif.v8i3.2751

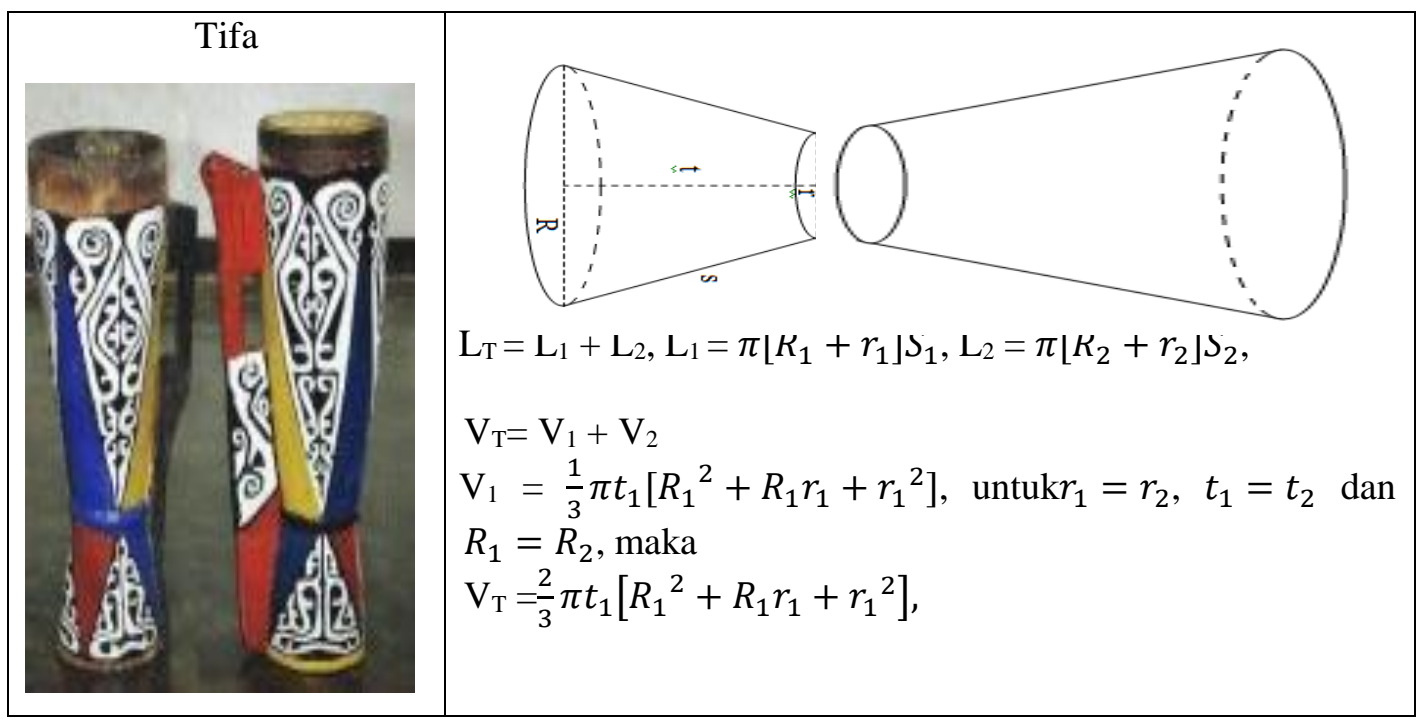

\section{PENUTUP}

Berdasarkan hasil kajian yang telah dibahas sebelumnya, dapat disimpulkan bahwa atap pada rumah tradisional rum som, rum sram, sram mankubui, serta alat musik tradisional yaitu tifa dari daerah Biak terdapat beberapa konsep matematika. Konsep yang dimaksud misalnya bentuk atap rum som adalah persegi panjang, trapesium, dan setengah elips. Bentuk atap rum sram adalah persegi panjang dan segitiga. Selanjutnya bentuk geometri atap sram mankubui adalah trapesium dan segitiga. Sedangkan tifa terlihat seperti dua buah kerucut terpancung yang digabung bagian atas dan bawah dengan ukuran berbeda. Pola atau bentuk atap rumah tradisional Suku Biak ini dapat menjadi alternatif sumber belajar Matematika pada materi konsep geometri. Kemudian dapat menambah wawasan peserta didik terhadap keberadaan matematika yang ada pada salah satu unsur budaya khususnya pada rumah tradisional dan alat musik Suku Biak. Serta meningkatkan motivasi belajar peserta didik dalam mengaitkan konsep-konsep matematika yang dipelajari dengan situasi dunia nyata. Selanjtnya, etnomatematika atap rumah tradisional dan alat musik Biak dapat lebih dipahami oleh semua masyarakat terutama para pendidik dan peserta didik dalam pembelajaran Matematika.

\section{DAFTAR PUSTAKA}

Aditya, D. Y. (2018). Eksplorasi unsur matematika dalam kebudayaan masyarakat jawa. Formatif: Jurnal Ilmiah Pendidikan MIPA, 7 (3), 253-261. http://10.30998/formatif.v7i3.2236

Albert Rumbekwan, (2014). Pelayaran Orang Biak di Teluk Cenderawasih abad XIX = Sailing of Biak People in The Gulf of Paradise Ninteenth Century. LibUI ind rda. Fakultas Ilmu Pengetahuan Budaya. Universitas Indonesia.

D'Ambrosio, U. (1985). Ethnomathematics and Its Place in The History and Pedagogy of Mathematics. For the Learning of Mathematics, 5(1), 44-48.

Heather, C .(2003). Success with Mathematics. New York: Routledge Taylorand Francis Group. 
Formatif: Jurnal Ilmiah Pendidikan MIPA

Vol. 8, No. 3, Desember 2018, pp. 175-184

p-ISSN: 2088-351X

e-ISSN: 2502-5457

DOI: http://dx.doi.org/10.30998/formatif.v8i3.2751

John, M. (1998). Ethnomathematics Concept, Definition and Research Perspectives, ISGEm Newsletter vol. II No. 1 Dec 1998.

James, R. (1982). How Students Can Own Mathematics. Journal of Ethnomathematics, 5 (1).

Kaplan, R. M., \& Saccuzzo, D. P. (1993). Psychological Testing: Principles. Applications and Issues, 3rd ed., Brooks Cole, Pacific Grove, CA.

Kahn, P. (2001). Studying Mathematics and Its Applications. Palgrave: Basingstoke.

Komandoko, G. (2010). Ensiklopedia Pelajar dan Umum. Pustaka Widyatama.

Musa, H. I (2007). Wasakwakwalwa. Radio FM Kano, unpublished Glorin (1980)

Sugiyono, (2009). Metode Penelitian Kuantitatif, Kualitatif dan R\&D. Bandung: Alfabeta.

Silas, Koibur interview, (2018). Sejarah Pembuatan Atap Rumah Tradisional Rum Som, Rum Sram, dan Rum Mankubui serta Alat Musik Tradisional Tifa. 16 Juni 2018. Kampung Sorido, Papua 
Formatif: Jurnal Ilmiah Pendidikan MIPA

Vol. 8, No. 3, Desember 2018, pp. 175-184

p-ISSN: 2088-351X

e-ISSN: 2502-5457

DOI: http://dx.doi.org/10.30998/formatif.v8i3.2751

@) $(\Theta \Theta \Theta$ 